\title{
El cine independiente como vehículo de contraanálisis sociopolítico en la Transición democrática española
} \author{
democratic transition \\ María Jesús Ruiz Muñoz \\ Profesora da Universidad de Málaga/ES \\ Correo electrónico: mariajesus@uma.es
}

Independent cinema as a vehicle to sociopolitical counter-analysis in Spain's

Resumo

Ao final dos anos trinta do século passado, começou a se desenvolver um cinema independente das estruturas industriais e das ideologias dominantes. Os anos sessenta serviram para a recuperação de um uso muito parecido do veículo cinematográfico em âmbitos como o das universidades francesas ou americanas. Inclusive na Espanha, se desenvolveu uma produção cinematográfica alternativa, ainda que de uma maneira muito menor devido às circunstâncias políticas e com certo atraso em relação a outros países.

Palavras-chave: cinema, independente, alternativo, contra-análise, Transição Espanhola.

Las investigaciones realizadas hasta ahora sobre el cambio que tuvo lugar en España como consecuencia de la transición a la democracia han abordado el tema desde una perspectiva predominantemente histórica y política. Sin embargo, resulta fundamental reflexionar acerca de la dimensión cultural para alcanzar una completa comprensión y definición del cambio que tuvo lugar en todos los sentidos durante aquellos años ${ }^{1}$.

La instauración de un régimen democrático tras una etapa dictatorial conlleva, en todos los casos, un lento proceso de reconstrucción política, económica y cultural. En este sentido, los vehículos culturales y los medios de comunicación, debido al eco y repercusión que tienen en la sociedad, se convierten en una pieza clave para la recuperación y el análisis de un pasado reciente cargado de fuertes implicaciones de toda índole, pero especialmente ideológicas y emotivas. Por su parte, el medio cinematográfico, debido a su poderosa eficiencia en la transmisión de normas sociales e incluso de consignas ideológicas, constituye un instrumento particularmente adecuado para estudiar el paso a la democracia en España.

Entre los estertores del franquismo y los comienzos del régimen democrático, se desarrolló en nuestro país una producción de voluntad contraria al sistema dictatorial e impulsora de diferentes valores conducentes al cambio democrático. En una situación que resultaba poco propicia incluso para la cinematografía industrial española, tuvieron aún menos cabida estas arriesgadas propuestas indepen-dientes, financiadas por medios propios, distribuidas con escasez de recursos y dirigidas en todo momento a un público más minoritario. Pero, precisamente, estas singularidades contribuyen enormemente a determinar que el estudio de este tipo de cine es una pieza clave para establecer el grado de transformación cultural que fue acometida en la etapa que nos ocupa.

Antes de ahondar en los particulares derroteros de las manifestaciones cinematográficas contraculturales del periodo, conviene matizar que la delimitación conceptual del "cine independiente" resulta una tarea compleja, puesto que esta denominación se ha convertido en
${ }^{1}$ Siguiendo este punto de vista, María Jesús Ruiz Muñoz realiza actualmente su tesis doctoral acerca del desarrollo del cine independiente en Andalucía durante la Transición, gracias a una beca de Formación de Personal Docente e Investigador de la Junta de Andalucía. 
${ }^{2}$ Una de las excepciones en este sentido es ROMERO DE ÁVILA, R.: El Cine independiente y experimental.Barcelona: Royal Books, 1995, y otra HERNÁNDEZ, J. y PÉREZ, P.: Voces en la niebla: el cine durante la Transición española (1973-1982).- Barcelona: Paidós Ibérica, 2004.

${ }^{3}$ Una reflexión en torno a los planteamientos para la definición del cine independiente puede encontrarse en: SÁNCHEZ ALARCÓN, I. y RUIZ MUÑOZ, M. J.: "¿Cine marginal, cine militante, cine clandestino? Actividad cinematográfica desarrollada en España contra el régimen de Franco durante la Transición Política (1973-1977)", en Treballs de comunicació. № 20, diciembre 2005. Consúltese también al respecto: SÁNCHEZ ALARCÓN, I. y RUIZ MUÑOZ, M. J.: "Definición y concepto del cine independiente: Una perspectiva comparativa entre el caso español y otras cinematografías". En PÉREZ PERUCHA, J. y POYATO, P.: XI Congreso Internacional de la Asociación Española de Historiadores del Cine. ¡Savia nutricia? El lugar del realismo en el cine español, tomo Il. Córdoba: Junta de Andalucía/ Consejería de Cultura, 2006. Pp. 171-179. una especie de cajón de sastre en el que se ha dado cabida desde películas de compromiso político hasta experiencias meramente esteticistas o formales. Por otra parte, la aproximación al concepto se encuentra también dificultada debido a que las fuentes secundarias que versan sobre el cine independiente lo abordan parcial-mente, centrándose en movimientos o períodos concretos, sin contemplar en profundidad cómo han evolucionado técnica, artística y conceptualmente este clase de manifestaciones ${ }^{2}$.

Las distintas obras que tienen cabida dentro del denominado «cine independiente» son tan diversas y difíciles de sistematizar que resultaría necesario llevar a cabo una revisión tanto de este concepto como de otros relacionados con él y que hay que distinguir por su interés, tales como «cine alternativo», «cine marginal» o «cine de autor». Asimismo, cabría considerar los títulos clasificados dentro del ámbito «amateur», «underground», «militante» 0 «clandestino», entre otros, por la peculiaridad de los matices que aportan a este amplio panorama. Pero, definitivamente, puesto que no constituye el objeto de este trabajo realizar un estudio conceptual pormenorizado, se partirá de la consideración genérica del "cine independiente" entendido como aquel que se aparta de los condicionantes de la industria, económica e ideológicamente, ya que inicialmente ésta es la acepción más común a la que se hace referencia con esta terminología. Por otra parte, se suele considerar que las denominaciones "independiente", "alternativo" y "marginal" actúan como sinónimos ${ }^{3}$.

En lo que respecta al clima en el que se desarrolló la actividad que analizamos en este texto, hay que recordar que la década que transcurrió desde mediados de los años sesenta hasta 1975 se caracterizó a nivel mundial por una marcada agitación política y social. El cine, como instrumento de reflejo y canalización de la sociedad, se hizo eco de las alteraciones vividas en este periodo, especialmente en los países de capitalismo desarrollado de la Europa Occidental, en Estados Unidos y en determinados lugares de América Latina. Las nuevas circunstancias se tradujeron tanto en una concepción diferente de la creación y de la realización cinematográfica como en la aparición de un tipo de público más exigente y reflexivo, con un creciente compromiso político, que demandaba un cine distinto.

En suma, el llamado cine independiente se convirtió en una herramienta preferente para la lucha política y en un elemento imprescindible para la creación contracultural en todos los foros en los que se produjeron los cambios que marcarían un nuevo carácter para el orden mundial y el sistema de valores en los años setenta. Como ejemplo de ello, cabría hacer mención de la trascendencia que alcanzó el cine anarquista en el París de Mayo del 68 o de la revolución que supuso el movimiento de cine underground en las universidades norteamericanas en la década de los sesenta y setenta.

En el ámbito más cercano al español, el de los países occidentales, el que podríamos denominar cine alternativo y, en algunas ocasiones, militante, se abrió camino como resultado de algunas iniciativas individuales. Pero también hay que destacar que se llevó a cabo una actividad cinematográfica importante por parte de agrupaciones constituidas en cooperativas de producción, entre las que podrían contarse Newsreel, que funcionó en Nueva York y San Francisco desde finales de 1967, o el amplísimo número de grupos surgidos de la izquierda 
política que recogieron las imágenes de los acontecimientos de París en mayo de 1968.

El documental, por delante de la ficción, pasó a ser el instrumento que sirvió como cauce fundamental para este cine independiente interesado por la realidad de su entorno. De hecho, fue entonces cuando este género demostró una gran capacidad para reflexionar sobre sus propias convenciones estilísticas y estructurales, además de definirse como un producto cultural especialmente sensible a la realidad de las circunstancias. ${ }^{4}$ Cabe destacar al respecto la figura del francés Jean-Luc Godard, uno de los realizadores más significativos de la producción alternativa en los años sesenta y setenta, cuya experiencia demuestra que la evolución que emprendió durante estos años el medio audiovisual no tuvo que ver sólo con la forma, ya que también adoptó manifestaciones acusadamente ideológicas y políticas. El ejemplo de Godard puede servir también para introducir una primera característica que diferencia la producción independiente que se realizó en España durante este periodo de la que se llevó a cabo en otros países occidentales. Se trata de que figuras como las del director francés o la del estadounidense Emile de Antonio fueron dotadas de un prestigio y una autoridad moral que en ningún momento tuvieron los realizadores que siguieron unos planteamientos similares en España, ya que existían una serie de causas estructurales que impedían que cualquiera actividad cinematográfica que se apartase de las tendencias dominantes se desarrollara y fuera conocida más allá de un ámbito minoritario.

Cuando en los años setenta comenzaron a desarrollarse iniciativas cinematográficas indepen-dientes en España, este tipo de manifestaciones alternativas ya estaban decayendo fuera de sus fronteras. Además, en nuestro país las mencionadas actividades tuvieron un alcance mucho menor debido a los particulares mecanismos arbitrados por la dictadura franquista, que mantuvieron una orientación encaminada a impedir el contacto de los ciudadanos con las ideas revolucionarias que circulaban en el exterior. Inmersos en semejante panorama, los integrantes de los sindicatos, los partidos políticos y la prensa alternativa, así como los representantes del arte y la intelectualidad opuestos al régimen se vieron condenados a llevar a cabo sus proyectos en la clandestinidad.

Pero también algunos privilegiados tuvieron la ocasión de mantener contactos esporádicos con los nuevos conocimientos y experiencias culturales que habían sido vetados en España, generalmente a través de breves estancias vacacionales en países como Francia, Italia o Alemania. Estos pequeños viajes permitieron que un reducido grupo de cineastas españoles tuviera la oportunidad de aproximarse a trabajos tan emblemáticos como los del grupo italiano Dziga Vertov, el colectivo francés Cinélutte, el cine de contrainformación del Newsreel americano, revistas como Cinéthique o festivales como el de Pésaro, nutriéndose así de la creatividad de los movimientos que se estaban desarrollando en otros lugares.

Con todo, para explicar exhaustivamente por qué la actividad cinematográfica desarrollada en España al margen del sistema no logró la misma repercusión que en otros países, resultaría insuficiente detenerse sólo en lo referente a las medidas represivas impuestas por el régimen. Debe tenerse en cuenta que otros factores, como la carencia de recursos o el difícil acceso a la formación, también influyeron en que aquí tuviesen menor eco las iniciativas puestas en marcha a través
${ }^{4}$ Cfr. NICHOLS, B.: La representación de la realidad. Cuestiones y conceptos sobre el documental. Barcelona: Paidós, 1997. Pp. 93-114. 
${ }^{5}$ Cfr. PÉREZ PERUCHA, J.: "El Surgimiento de cines nacionales en la periferia industrial". En VV.AA. Historia del cortometraje español. Madrid: Festival de Cine de Alcalá de Henares / Comunidad de Madrid / Fundación Colegio del Rey / Filmoteca de la Generalitat Valenciana / Caja de Asturias / SGAE, 1996. Pp 197-207.

${ }^{6}$ Aún con la parcialidad que implica ser uno de los protagonistas del devenir del cine independiente en nuestro país, Llorenç Soler ha establecido una interesante diferenciación entre el cine marginal producido en Madrid y el que se realizó en Barcelona, atendiendo al desigual grado de efervescencia social y política de ambas ciudades: en Madrid, las producciones independientes se centraron en el reflejo de una traumatizada generación de posguerra, mientras Cataluña vivía problemas de inmigración y luchas obreras y reivindicaba una identidad diferenciada a través de este tipo de películas. SOLER, LI. Historia del cine independiente en España 1960-1975 (Inédito). de cooperativas cinematográficas y, más aún, aquéllas que fueron realizadas a expensas de esfuerzos individuales. Otra característica específica que aparta la producción independiente española de la mayoría de los casos es el denominado «cine de las nacionalidades» ${ }^{5}$, que responde a una necesidad de recuperar la identidad cultural y política negada por la dictadura franquista en determinados ámbitos territoriales.

En el caso español, la producción independiente apareció vinculada a la utilización del formato 16 $\mathrm{mm}$, aunque también se ajustan a los parámetros de este tipo de cine muchos filmes de formatos inferiores e incluso algunos de $35 \mathrm{~mm}$. Como precursores de esta clase de manifestaciones alternativas, cabría citar algunos títulos realizados en Cataluña a principios de los sesenta, entre ellos Viernes Santo (Joan Gabriel Tharrats, 1960), Notas sobre la emigración (Jacinto Esteva Grewe, 1960) o El alegre Paralelo (Enric Ripoll-Freixes, 1964), que no supusieron más que ejemplos aislados en su momento.

Los focos que polarizaron la aparición del nuevo movimiento de cooperativas contrario al sistema entre 1965 y 1966 fueron Madrid y Barcelona, y cabe destacar las figuras de Adolfo Arrieta o Llorenç Soler como algunos de sus iniciadores. En ambos lugares se desarrollaron actividades de carácter esporádico, como las que se concretan en Madrid a través de una estructura cooperativa apoyada por la revista Nuestro cine, y que supone la participación de cineastas que luego pasarían a la producción industrial, como Emilio Martínez Lázaro o Alfonso Ungría. ${ }^{6}$

La cinematografía independiente como tal irrumpió a mediados de la década de sesenta para consolidarse posteriormente a través de diversas iniciativas llevadas a cabo fundamentalmente en Cataluña. Sobresalen al respecto las actividades desarrolladas por la Central del Curt, que se constituyó en 1974 como cooperativa para la difusión de títulos independientes, y las tareas acometidas por la Cooperativa de Cine Alternativo, un grupo de producción que estableció los propios de la central utilizando los ingresos obtenidos por la distribución de películas y que realizó un número considerable de documentales para contribuir al análisis, denuncia y difusión de numerosas causas relacionadas con la lucha obrera.

Para algunos, el mejor momento para las películas marginales se inició entre 1968 y 1971, gracias a la contribución de cineastas como Pere Portabella, realizador y productor que intervino también en las tareas docentes del Institut del Teatre y de la Escola Ayxelà, de donde partieron muchas de las iniciativas del cine alternativo en la provincia barcelonesa durante aquellos años. Sin embargo, el primer intento organizado para la producción y distribución de este tipo de material fílmico debe ubicarse en 1974, cuando la Cooperativa de Cinema Alternatiu y la Central del Curt, surgida por la iniciativa de dos miembros de los ámbitos cineclubísticos de Barcelona, Josep Miquel Martí i Rom y Joan Martí i Vals, comenzaron a actuar indisolublemente unidas en todas y cada una de estas ramas de la actividad cinematográfica, primero sólo en el ámbito catalán y luego en el resto del país. Los catálogos distribuidos por la Central, además de una serie de películas de vocación inequívocamente marginal, dirigidas por realizadores catalanes y de otros lugares del territorio nacional, incluían también títulos clásicos, como Un perro andaluz (Luis Buñuel) o Tres cantos a Lenin (Dziga Vertov), ambas de 
1929. Evidentemente, se trataba de un material que hubiese sido difícil o imposible de distribuir comercialmente a través de otros canales. Por todo lo expuesto, el propio colectivo de sus autores se encargó de gestionar la entidad, que mantuvo un gran desarrollo hasta 1980, fecha en la que empezó su declive como consecuencia de las cambiantes circunstancias sociopolíticas hasta que se extinguió en 1984.

La Central del Curt nunca demostró una adscripción política clara. Sin embargo, puede reseñarse la existencia de cineastas y agrupaciones con un comportamiento militante más marcado. Es el caso del Colectivo de Cine de Clase, encabezado por Helena Lumbreras, que en el periodo tratado fue responsable con Mariano Lisa de los títulos El campo para el hombre (1975), sobre la situación de explotación del campesinado español, y $O$ todos $o$ ninguno (1976), que contribuyeron a poner de manifiesto problemas obreros de gran relevancia durante estos años. Además, siguiendo su tradición histórica, el Partido Comunista también cobijó un número considerable de iniciativas de este signo. El clandestino Group de Producció, integrado, entre otros, por Pere Ignasi Fages, Pere Joan Ventura o Manuel Esteban, por ejemplo, surgió directamente vinculado al Partit Socialista Unificat de Catalunya (PSUC). Todos ellos colaboraron en las "volti", redes de distribución clandestina de este tipo de material, para las que contaron con la ayuda decisiva del partido en Francia ${ }^{7}$. Por su parte, Andrés Linares fue el líder del Colectivo de Cine de Madrid, que llevó a cabo sus actividades a la sombra del PCE en la capital de España.

El contexto de una Transición política pactada sobre la base del olvido no supuso el punto de partida más idóneo para que el público se mostrase receptivo a este tipo de propuestas radicales y transgresoras, incluso cuando el final de los mecanismos represivos del régimen permitió el estreno de las películas alternativas. Asimismo, cabe subrayar que, tratándose de un momento de crisis económica generalizada y con un nivel cultural relativamente bajo, la mayoría de los espectadores de aquella España carecían de una predisposición adecuada para acoger este cine.

Otra muestra de la producción marginal que se lleva a cabo durante la Transición está constituida por aquellos documentales en los que la Guerra Civil sirve de referente temático y como excusa para intentar recuperar una historia hurtada por el franquismo. Uno de los primeros títulos alternativos referidos de manera explícita a esta etapa de nuestro pasado anterior al régimen de Franco es Entre la esperanza y el fraude (1974), una película realizada por los estudiantes de periodismo Bartolomeu Vilà y Joan Simó, que la difundieron desde el ámbito de la Cooperativa de Cinema Alternatiu.

Entre las obras que optan por una reflexión histórica, también es necesario destacar las aportaciones de Basilio Martín Patino. Las pautas del documental reflexivo se mezclan con la contestación política en los títulos que el director realiza en este periodo, Canciones para después de una guerra (1976), Queridísimos Verdugos (1977) o Caudillo (1977), todos sobre la represión ejercida por el régimen franquista. Pero, además de reflexionar sobre el pasado, los cineastas españoles con una vocación alternativa también se ocupan a lo largo de estos años de analizar las claves del presente y otorgarles un puesto de honor a algunos de sus protagonistas más rebeldes y desconocidos. De este modo, películas más minoritarias, como Ocaña,
${ }^{7}$ Crónica d'una mirada (TVC / Mòn Diplomàtic, 2003). Episodio 3, "Xarxes clandestines". 
${ }^{8}$ Sobre las circunstancias que determinaron el funcionamiento y desaparición de la Semana Internacional de Cine de Benalmádena, puede consultarse SÁNCHEZ ALARCÓN, I. (coord.); JIMÉNEZ GÁMEZ, A..; MELIVEO NOGUÉS, P.; RUIZ MUÑOZ, M. J.; TERUEL RODRÍGUEZ, L.: "La Semana de Cine de Autor de Benalmádena: canales alternativos de difusión cinematográfica en Málaga durante la Transición". En COMPANY, A.; PONS, J.; SERRA, S. (eds.): La comunicaciò audiovisual en la història. Vol. II. Palma de Mallorca: Servei de Publicacions i Intercanvi Cientific de la Universitat de les Illes Balears, 2003. Pp. 981-992. retrat intermitent (Ventura Pons, 1978), sirven para dar la voz a personajes hasta entonces reprimidos por la dictadura.

El ámbito preferente de exhibición del cine marginal, tanto del material de los colectivos de cine militante como de las películas resultantes de iniciativas individuales, no se circunscribió a los canales centrados en el medio cinematográfico, como festivales o cineclubs. Las universidades y otros centros de enseñanza, las asociaciones culturales y los colectivos vecinales, entre otros, también sirvieron de cauces favorables para su divulgación entre un público heterogéneo $\mathrm{y}$, por lo tanto, con diversos niveles de formación y predisposición para acoger este tipo de producciones.

A pesar de que las inquietudes políticas vigentes en la sociedad española de los años de la Transición motivaran la existencia de determinados ámbitos favorables a la difusión de los títulos alternativos, a mediados de los años setenta, la falta de homogeneidad de intenciones y criterios sumada a grandes dificultades de todo orden provocaron una distribución aleatoria y esporádica del cine independiente realizado en España. Debido a la represión ejercida por el régimen, las posibilidades de venta se circunscribían exclusivamente al extranjero $\mathrm{y}$, además, eran escasas. De hecho, hacia 1974, proliferaron las manifestaciones y los certámenes dedicados al cine marginal filmado en Super $8 \mathrm{~mm}$, a la vez que, sobre todo a partir del eco internacional que alcanzó el Proceso de Burgos, hubo cada vez más televisiones de otros países interesadas en comprar imágenes de las revueltas que se producían en España y a las que no se podía acceder a través de fuentes oficiales por razones obvias.

También es necesario subrayar la función como foros políticos que desempeñaron algunos certámenes cinematográficos, que entrarían en crisis con la llegada de la democracia, como fue el caso de la Semana Internacional de Cine de Benalmádena $^{8}$. El declive de estos festivales estuvo íntimamente ligado a la pérdida de sentido de las implicaciones ideológicas o reivindicativas que los habían convertido en focos de atracción. Pero esta situación no se explicaría del todo sin considerar además que, con el fin de la censura, el público pudo tener un acceso sin restricciones a películas que antes habían estado prohibidas.

A modo de síntesis, cabría afirmar que el cine que se produjo en la España de los años setenta, aunque no llegase a contar con la repercusión que años antes tuvieron manifesta-ciones similares en otros países, resulta relevante por su contribución al cuestionamiento de la forma de organización política entonces vigente y por el empeño puesto para que los espectadores fuesen conscientes de la inercia en la que los quería tener sumidos la organización colectiva. En un contexto en el que las instituciones no daban respuesta a las necesidades de cambio, este tipo de películas sirvió, como otras actividades culturales, para canalizar las inquietudes de quienes pretendían la instauración de la democracia, aunque en España no se generalizase una conciencia clara de Transición cultural hasta mucho después ${ }^{9}$.

\section{Abstract}

An independent cinema current, free from marketing structures and main stream ideologies, started to develop in the late thirties. The sixties brought back a similar use of this type of cinema in French and American universities. An alternative cinema production was developed even in Spain, although in smaller scale due to political circumstances. It was developed rather 
late compared with other countries.

UNAM.

KEY WORDS: cinema, independent, alternative, counter-analysis, Spanish Transition

Bibliografia:

ANTOLÍN, M. (1979) Cine marginal en España. Valladolid: Semana Internacional de Cine de Valladolid.

CAPARRÓS LERA, J. M. (1978): El cine político visto después del franquismo. Barcelona: Dopesa.

HERNÁNDEZ RUIZ, J. y PÉREZ, P. (2004): Voces en la niebla: el cine durante la Transición española (19731982). Barcelona, Paidós Ibérica.

LINARES, A. (1976): El cine militante. Madrid: Miguel Castellote.

ROMAGUERA, J. y SOLER, LI. (2006): Historia crítica y documentada del cine independiente en España (1955-1975). Barcelona: Laertes.

ROMERO DE ÁVILA, Rafael: El cine independiente y experimental. Barcelona: Royal Books.

TRENZADO ROMERO, M. (1999): Cultura de masas y cambio político: el cine español de la Transición. Madrid: Centro de Investigaciones Sociológicas. VIOTA, P. (1982): El cine militante en España. Méjico:

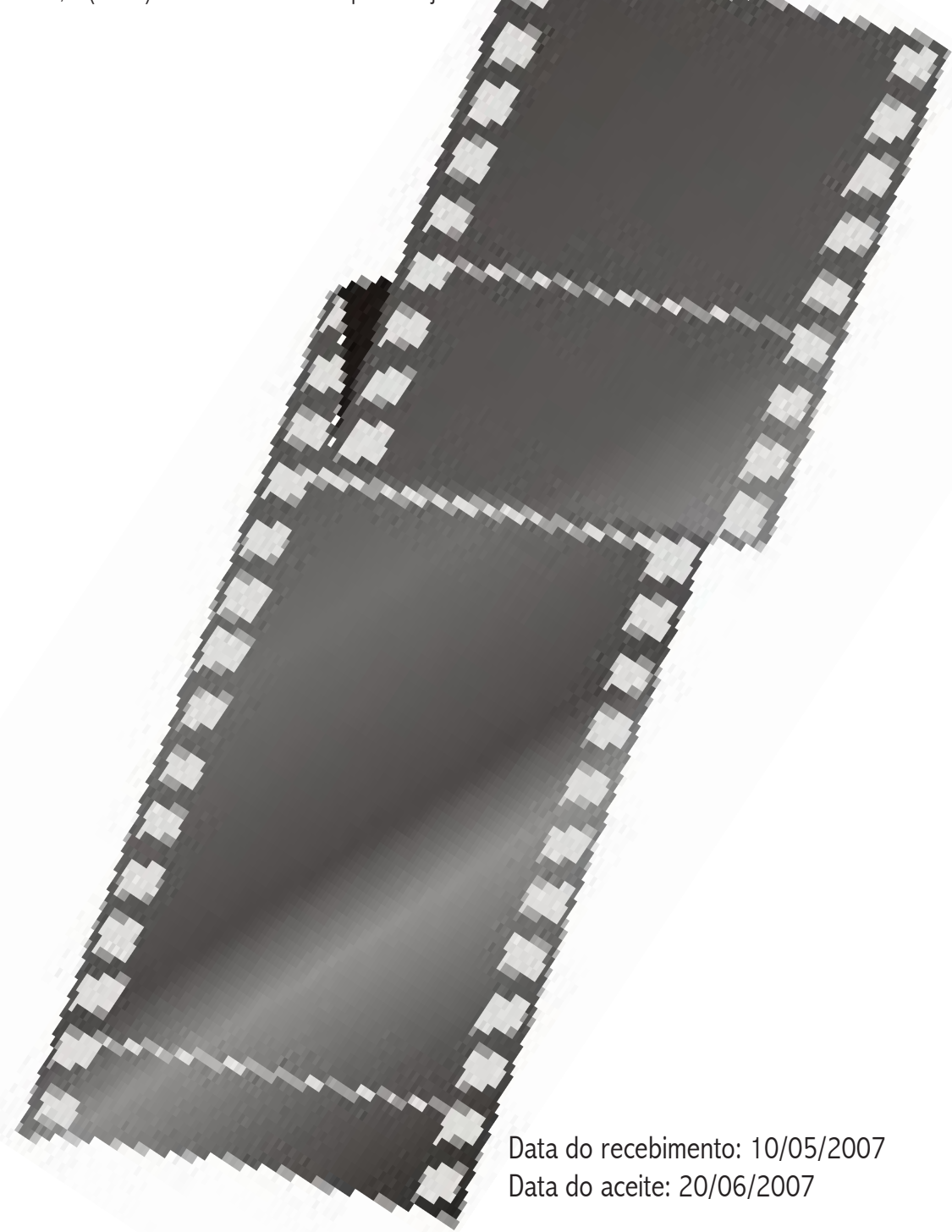

${ }^{9}$ Cfr. TUSELL, J.: La Transición española a la democracia. Madrid: Historia 16, 1999. Pp. 186-187.

María Jesús Ruiz Muñoz. El cine independiente como vehículo de contraanálisis sociopolítico en la trasición democrática española. Comunicação e Informação, V 10, nº 1: pág 27 - 33 - jan/jun. 2007. 